\title{
Relationship between Acute Phase of Chronic Periodontitis and Meteorological Factors in the Maintenance Phase of Periodontal Treatment: A Pilot Study
}

\author{
Noriko Takeuchi ${ }^{1, *}$, Daisuke Ekuni ${ }^{1}$, Takaaki Tomofuji ${ }^{1,2}$ and Manabu Morita ${ }^{1}$ \\ 1 Departments of Preventive Dentistry, Okayama University Graduate School of Medicine, Dentistry \\ and Pharmaceutical Sciences, 2-5-1 Shikata-cho, Kita-ku, Okayama 700-8558, Japan; \\ E-Mails: dekuni7@md.okayama-u.ac.jp (D.E.); tomofu@md.okayama-u.ac.jp (T.T.); \\ mmorita@md.okayama-u.ac.jp (M.M.) \\ 2 Advanced Research Center for Oral and Craniofacial Sciences, Okayama University Dental School, \\ 2-5-1 Shikata-cho, Kita-ku, Okayama 700-8558, Japan
}

* Author to whom correspondence should be addressed; E-Mail: takeuti@md.okayama-u.ac.jp (N.T.); Tel.: +81-86-235-6712; Fax: +81-86-235-6714.

Academic Editor: Paul Tchounwou

Received: 3 July 2015 / Accepted: 31 July 2015 / Published: 5 August 2015

\begin{abstract}
The acute phase of chronic periodontitis may occur even in patients during supportive periodontal therapy. However, the details are not fully understood. Since the natural environment, including meteorology affects human health, we hypothesized that weather conditions may affect occurrence of acute phase of chronic periodontitis. The aim of this study was to investigate the relationship between weather conditions and acute phase of chronic periodontitis in patients under supportive periodontal therapy. Patients who were diagnosed with acute phase of chronic periodontitis under supportive periodontal therapy during 2011-2013 were selected for this study. We performed oral examinations and collected questionnaires and meteorological data. Of 369 patients who experienced acute phase of chronic periodontitis, 153 had acute phase of chronic periodontitis without direct-triggered episodes. When using the autoregressive integrated moving average model of time-series analysis, the independent covariant of maximum hourly range of barometric pressure, maximum hourly range of temperature, and maximum daily wind speed were significantly associated with occurrence of acute phase of chronic periodontitis $(p<0.05)$, and $3.1 \%$ of the variations in these occurrence
\end{abstract}


over the study period were explained by these factors. Meteorological variables may predict occurrence of acute phase of chronic periodontitis.

Keywords: acute phase; chronic periodontitis; barometric pressure; supportive periodontal therapy; autoregressive integrated moving average model

\section{Introduction}

Periodontitis is one of the most widespread chronic diseases and is characterized by gingival bleeding, periodontal pocket formation, destruction of connective tissue attachment, and alveolar bone resorption. Based on a Japanese national survey, $42.5 \%$ of Japanese exhibited periodontitis [1]. The primary etiological agent for periodontitis is dental plaque bacteria [2,3]. The majority of periodontal tissue destruction is caused by abnormal host responses to these microorganisms and their products $[4,5]$.

For the long-term stability of successfully treated periodontitis, supportive periodontal therapy (periodontal maintenance) is needed and is regarded as an integral part of overall periodontal management [6-8]. Although dentists have been making every effort to maintain periodontal health and prevent tooth loss during supportive periodontal therapy, acute phase of chronic periodontitis may occur in patients and has been regarded as one of the possible complications of supportive periodontal therapy [9]. A review [10] suggested that there were intraoral risk factors related to acute phase of chronic periodontitis. However, clinicians sometimes encounter patients suffering from periodontal abscess without any intraoral factors. Therefore, there may be a relationship between acute phase of chronic periodontitis and extraoral factors.

The natural environment including meteorology affects human health. Weather conditions have been found to be related to blood pressure [11-13], myocardial infarction [14,15], heatstroke [16], stroke [17], paediatric trauma [18], mortality [19], asthma [20,21], depression [22,23], rheumatoid arthritis [24,25], and pain in general [26]. In dentistry, some recent research suggests that meteorology is related to temporomandibular disorders [27] and oral pain [28].

Based on these findings, we hypothesized that weather conditions may cause occurrence of acute phase of chronic periodontitis. The aim of this study was to investigate the relationship between weather conditions and occurrence of acute phase of chronic periodontitis in patients under supportive periodontal therapy. Since meteorological variables influence one another [29], we chose temperature, rainfall, barometric pressure, wind speed, hours of sunlight, and humidity as meteorological variables.

\section{Methods}

\subsection{Study Population}

This study was performed at the Preventive Dentistry clinic in Okayama University Hospital in Japan from November 2011 to November 2013. In the clinic, all patients received supportive periodontal therapy that included non-surgical periodontal therapy consisting of oral examination, oral hygiene instructions, supra/sub-gingival debridement and scaling, and root-planing every 3-4 months [30]. The patients who were diagnosed with acute phase of chronic periodontitis under supportive periodontal therapy were selected for this study. Criteria for the acute phase of chronic periodontitis included at least two of the 
following clinical signs or symptoms; pain, swelling, redness or a feeling of warmth in the periodontal lesion [31,32]. Exclusion criteria were as follows: patients who had cancer, hospitalized patients, and patients with missing data. The patients who lived outside of Okayama's local meteorological area were also excluded. This study was approved by the Ethics Committee of Okayama University Hospital (No. 502, 692). After obtaining written informed consent, the dentists completed a detailed medical questionnaire and oral examination as follows.

\subsection{Oral Examination}

All clinical procedures were performed by four trained and calibrated dentists (T.T., M.M., D.E., and N.T.). To distinguish other diseases including apical periodontitis, tooth fracture and trauma, acute phase of chronic periodontitis were confirmed by X-ray and or oral examination.

\subsection{Questionnaires}

The dentists took the history of acute phase of chronic periodontitis. They collected information about the date, place, and possible trigger that the patients were aware of, and any acute symptoms, such as physical stress, mental stress, occlusal trauma, insufficiency for oral hygiene, and so on. When the patients could not identify the trigger clearly and dentists could not determine the clinical factors affecting acute phase of chronic periodontitis, such cases were defined as acute phase of chronic periodontitis without direct-triggered episodes.

\subsection{Meteorological Measurements}

Meteorological data were acquired from the local meteorological office at Okayama City. The data included the following: (1) mean daily wind speed (m/s), (2) maximum daily wind speed (m/s), (3) minimum daily wind speed $(\mathrm{m} / \mathrm{s})$, (4) mean daily barometric pressure $(\mathrm{hPa}),(5)$ maximum daily barometric pressure $(\mathrm{hPa}),(6)$ minimum daily barometric pressure $(\mathrm{hPa}),(7)$ daily range of barometric pressure $(\mathrm{hPa}),(8)$ maximum hourly increase in barometric pressure $(\mathrm{hPa}),(9)$ maximum hourly decrease in barometric pressure $(\mathrm{hPa}),(10)$ total hours of sunlight, (11) total daily rainfall $(\mathrm{mm}),(12)$ mean daily temperature $\left({ }^{\circ} \mathrm{C}\right),(13)$ maximum daily temperature $\left({ }^{\circ} \mathrm{C}\right),(14)$ minimum daily temperature $\left({ }^{\circ} \mathrm{C}\right),(15)$ daily range of temperature $\left({ }^{\circ} \mathrm{C}\right),(16)$ maximum hourly increase in temperature $\left({ }^{\circ} \mathrm{C}\right),(17)$ maximum hourly decrease in temperature $\left({ }^{\circ} \mathrm{C}\right),(18)$ mean daily humidity $(\%),(19)$ maximum daily humidity (\%), (20) minimum daily humidity (\%), and (21) daily humidity range [29].

\subsection{Statistical Analysis}

A multivariate autoregressive integrated moving average model (ARIMA) was performed to identify whether meteorological variables might predict occurrence of acute phase of chronic periodontitis using Box-Jenkins methodology [29,33]. Models were identified by determining ARIMA model orders (p, d, q) using autocorrelation and partial autocorrelation. The model parameters were estimated by the unconditional least squares method. Finally, the adequacy of the model was checked and statistical significance of the parameters determined [33]. After identifying the multivariate transfer function models, the cross-correlation function was determined by estimating the correlations between occurrence of acute 
phase of chronic periodontitis at different time lags and metrological valuables. The final model was determined by the highest biological plausibility and determination coefficient (r2). All data were analyzed using the Statistical Package for the Social Sciences (21.0J for Windows; SPSS Japan, Tokyo, Japan). Values of $p<0.05$ were considered to represent statistically significant differences.

\section{Results}

Table 1 presents the characteristics of the study population. Of a total of 20,034 patients who had received supportive periodontal therapy at the hospital clinic, 369 patients developed acute phase of chronic periodontitis ( $1.84 \%$ of all patients). The number of acute phase of chronic periodontitis without direct-triggered episodes was $153(0.76 \%)$ and the mean age of patients was 68.7 years $(\mathrm{SD}=11.2)$. The proportion of females was $73.9 \%$.

Table 1. Characteristics of the study population.

\begin{tabular}{|c|c|c|c|}
\hline Age & Male & Female & Total \\
\hline \multicolumn{4}{|c|}{ Patients Who Had Received Supportive Periodontal Therapy } \\
\hline $20-29$ & 114 & 138 & 252 \\
\hline $30-39$ & 135 & 444 & 579 \\
\hline $40-49$ & 434 & 922 & 1356 \\
\hline $50-59$ & 726 & 2235 & 2961 \\
\hline $60-69$ & 1962 & 4766 & 6728 \\
\hline $70-79$ & 1842 & 4031 & 5873 \\
\hline $80-$ & 942 & 1343 & 2285 \\
\hline Total & 6155 & 13,879 & 20,034 \\
\hline \multicolumn{4}{|c|}{ Patients with Acute Phase of Chronic Periodontitis } \\
\hline $20-29$ & 0 & 0 & 0 \\
\hline $30-39$ & 1 & 4 & 5 \\
\hline $40-49$ & 3 & 9 & 12 \\
\hline $50-59$ & 9 & 25 & 34 \\
\hline $60-69$ & 33 & 114 & 147 \\
\hline $70-79$ & 34 & 89 & 123 \\
\hline $80-$ & 13 & 35 & 48 \\
\hline Total & 93 & 276 & 369 \\
\hline \multicolumn{4}{|c|}{ Patients with Acute Phase of Chronic Periodontitis without Direct-Triggered Episodes } \\
\hline $20-29$ & 0 & 0 & 0 \\
\hline $30-39$ & 0 & 2 & 2 \\
\hline $40-49$ & 1 & 4 & 5 \\
\hline $50-59$ & 6 & 7 & 13 \\
\hline $60-69$ & 10 & 48 & 58 \\
\hline $70-79$ & 18 & 40 & 58 \\
\hline $80-$ & 5 & 12 & 17 \\
\hline Total & 40 & 113 & 153 \\
\hline
\end{tabular}


The mean probing pocket depth at teeth with occurrence of acute phase of chronic periodontitis was $5.1 \pm 2.5 \mathrm{~mm}$ among patients without direct-triggered episodes. The number of teeth with mobility was $37(24.2 \%)$.

The correlation between occurrence of acute phase of chronic periodontitis without direct-triggered episodes and meteorological parameters is shown in Table 2. Based on the correlation of the results, the final model was predicted using the ARIMA model (Table 3). The independent covariants, namely maximum hourly range (decrease) of barometric pressure, maximum hourly range (increase) of temperature, and maximum daily wind speed were significantly associated with occurrence of acute phase of chronic periodontitis without direct-triggered episodes $(p<0.05)$. The determination coefficient $\left(r^{2}\right)$ of the final model was $0.031 \%$ or $3.1 \%$ of the variations in occurrence of acute phase of chronic periodontitis without direct-triggered episodes over the study period were explained by the factors included in the model.

Table 2. Significant cross correlations with acute phase of chronic periodontitis without direct-triggered episodes.

\begin{tabular}{lcc}
\hline Parameter & $\boldsymbol{r}$ & $\boldsymbol{P}$ Value \\
\hline Wind speed (m/s) & & \\
\hline Mean daily wind speed & 0.062 & $<0.001$ \\
Maximum daily wind speed & -0.015 & 0.027 \\
Minimum daily wind speed & Omitted & \\
\hline Barometric pressure (hPa) & & \\
\hline Mean daily barometric pressure & Omitted & \\
Maximum daily barometric pressure & Omitted & \\
Minimum daily barometric pressure & Omitted & \\
Daily range of barometric pressure & 0.019 & $<0.001$ \\
Maximum hourly increase in barometric pressure & 0.133 & 0.002 \\
Maximum hourly decrease in barometric pressure & 0.099 & $<0.001$ \\
Total hours of bright daily sunshine (h) & Omitted & \\
Total daily rainfall (mm) & Omitted & \\
\hline Temperature ( $\left.{ }^{\circ} \mathbf{C}\right)$ & & \\
\hline Mean daily temperature & -0.005 & 0.015 \\
Maximum daily temperature & -0.005 & 0.009 \\
Minimum daily temperature & -0.004 & 0.015 \\
Daily range of temperature & Omitted & \\
Maximum hourly increase in temperature & -0.05 & 0.018 \\
Maximum hourly decrease in temperature & Omitted & \\
\hline Humidity (\%) & & \\
\hline Mean daily humidity & Omitted & \\
Maximum daily humidity & Omitted & \\
Minimum daily humidity & Omitted & \\
Daily humidity range & Omitted & \\
\hline & & \\
\hline & & \\
\hline
\end{tabular}


Table 3. Multivariate time-series analysis model for acute phase of chronic periodontitis without direct-triggered episodes $\left(r^{2}=0.031\right)$.

\begin{tabular}{lcccc}
\hline Term & Lag Time $^{\text {a }}$ & Coefficient (S.E.) $^{\mathbf{b}}$ & T Ratio & $\boldsymbol{P}$ Value \\
\hline $\begin{array}{l}\text { Maximum hourly decrease } \\
\text { in barometric pressure }\end{array}$ & 2 & $0.098(0.031)$ & 3.156 & 0.002 \\
$\begin{array}{l}\text { Maximum hourly increase } \\
\text { in temperature }\end{array}$ & 1 & $0.046(0.018)$ & 2.473 & 0.014 \\
\begin{tabular}{l} 
Maximum daily wind speed \\
\hline
\end{tabular} & 3 & $-0.015(0.006)$ & -2.501 & 0.013 \\
\hline
\end{tabular}

${ }^{\mathrm{a}}$ Represents the delay necessary to observe the effect (in days). ${ }^{\mathrm{b}}$ Indicates the size and the direction of the effect.

\section{Discussion}

To the best of our knowledge, this is the first epidemiological study to assess the relationship between occurrence of acute phase of chronic periodontitis and meteorological variables during the maintenance phase of periodontal treatment. In this study, ARIMA model analysis showed that maximum hourly decrease in barometric pressure, maximum hourly increase in temperature, and maximum daily wind speed were significantly associated with occurrence of acute phase of chronic periodontitis. In this model, $3.1 \%$ of the variations in occurrence of acute phase of chronic periodontitis over the study period were explained by these factors. Our results provide new findings in the acute phase of chronic periodontitis development. In addition, occurrence of acute phase of chronic periodontitis seems to occur one to three days after changes in meteorological variables. It is feasible that there is a response time lag in which meteorological variables induce pathological changes in periodontal tissue. In the occurrence of acute phase of chronic periodontitis, the first step may be the invasion of bacteria into the soft tissues surrounding the periodontal pocket, which will develop an inflammatory process [34]. Bacterial pathogens attract inflammatory cells to induce chemokines and cytokines, and modulate the inflammatory response during 2-72 h [35-38]. These findings might support the time lag.

In this study, maximum hourly decrease in barometric pressure was related to occurrence of acute phase of chronic periodontitis. A case report suggested that sudden decreases in barometric pressure when on an airplane can influence the disease activity of patients with acute apical periodontitis [39], which supports our findings. Barometric pressure may have an effect on myopia [40], passenger discomfort on aircrafts [41], sleep disordered breathing [42], deep venous thrombosis [43], and oral pain [28,44]. In an animal model, decreases in barometric pressure induce pain and increase blood pressure and heart rate, suggesting the direct effects of barometric pressure on sympathetic nerve activity and the indirect effects of activation of the peripheral nociceptive and/or mechano-receptive fibers [45]. Although it is difficult to explain the relationship between barometric pressure and occurrence of acute phase of chronic periodontitis, there may be a possible mechanism or hormonal changes [46]. Decreases in barometric pressure possibly modulate the environment of hormones such as adrenaline [46]. Some hormones have direct effects on the growth of periodontitis-related bacteria in vitro [47]. Thus, decreases in barometric pressure might indirectly contribute to occurrence of acute phase of chronic periodontitis. However, further studies are required.

Changes in temperatures contribute to the observed temperature-related mortality [48-51] and increased cardiovascular and respiratory risk $[52,53]$. Occurrence of acute phase of chronic periodontitis 
was also related to maximum hourly increase in temperature in this study. Changes in temperature can control blood biomarkers. For example, cumulative increases in fibrinogen and plasminogen activator inhibitor type 1 in diabetes patients are observed in association with a $5{ }^{\circ} \mathrm{C}$ temperature decrement [54]. It is also known that increased C-reactive protein and interleukin- 6 occur with a $10{ }^{\circ} \mathrm{C}$ temperature decrement [55]. Therefore, the inflammatory process in periodontal tissue may be partially affected by the temperature-related changes in blood biomarkers. Further studies are required to explore the exact mechanisms that promote the association between occurrence of acute phase of chronic periodontitis and changes in temperature.

Wind speed may have an indirect effect on the severity and frequency of air pollution occurrence in respiratory allergic disease [56]. It is also reported that higher wind speed provides a small increase in the risk of back pain [57]. In the present study, occurrence of acute phase of chronic periodontitis was negatively related to maximum daily wind speed. This supports the concept that not only barometric pressure and temperature but also wind speed can affect health, including periodontal condition.

The present comprehensive epidemiological study describes the influence of changes in meteorological valuables on occurrence of acute phase of chronic periodontitis and yields evidence that this can be a phenomenon of everyday life. It is commonly accepted that the weather itself may influence the well-being of individuals. Therefore, dentists should be aware of the relationship and inform their patients about the weather being one of the probable reasons for certain complaints.

In this study, the acute phase of chronic periodontitis during supportive periodontal therapy was $1.84 \%$ of all patients. Previous studies report that the prevalence of periodontal abscess is $1.04 \%-27.5 \%$ [34,58-62]. The prevalence in this study was within the range, which suggests that participants were not limited to a specific group and the results may be generalized to a various populations.

Our study has some limitations. First, the experimental period (two years) may be too short to investigate the seasonal effects. A long-term study will be required to clarify it. Second, the number of patients was small in this study. Future study needs a large number of patients. Third, meteorological data were only acquired from one area. Because other areas where occurrence occurred were quite few, we selected cases in a limited area. A multicenter study including more areas will be required. Fourth, $3.1 \%$ of the variations in occurrence of acute phase of chronic periodontitis without direct-triggered episodes were explained by meteorological factors. However, since $41.4 \%$ of occurrence was of unknown origin in this study, other explanation such as a minor shift in the microorganisms should be considered. Further studies are needed to clarify the details of acute phase of chronic periodontitis without direct-triggered episodes.

\section{Conclusions}

Maximum hourly decrease in barometric pressure, maximum hourly increase in temperature, and maximum daily wind speed were significantly associated with occurrence of acute phase of chronic periodontitis without direct-triggered episodes. In the model, $3.1 \%$ of the variations in the occurrence of acute phase of chronic periodontitis over the study period could be explained by these factors. 


\section{Acknowledgments}

The authors are grateful to Keiko Kimura for data analysis. This work was supported by Grants-in-Aid for Scientific Research (No. 40157904 and No. 25670892) from the Ministry of Education, Culture, Sports, Science and Technology, Tokyo, Japan.

\section{Author Contributions}

N.T., D.E., T.T. and M.M. conceived and planned the project and wrote the manuscript. They also conducted oral examinations. N.T. performed data entry and conducted statistical analysis.

\section{Conflicts of Interest}

The authors declare no conflict of interest.

\section{References}

1. Ojima, M.; Hanioka, T.; Tanaka, K.; Inoshita, E.; Aoyama, H. Relationship between smoking status and periodontal conditions: Findings from national databases in Japan. J. Periodont. Res. 2006, 41, 573-579.

2. Madianos, P.N.; Bobetsis, Y.A.; Kinane, D.F. Generation of inflammatory stimuli: How bacteria set up inflammatory responses in the gingiva. J. Clin. Periodontol. 2005, 32, 57-71.

3. Colombo, A.P.; Boches, S.K.; Cotton, S.L.; Goodson, J.M.; Kent, R.; Haffajee, A.D.; Socransky, S.S.; Hasturk, H.; van Dyke, T.E.; Dewhirst, F.; et al. Comparisons of subgingival microbial profiles of refractory periodontitis, severe periodontitis, and periodontal health using the human oral microbe identification microarray. J. Periodontol. 2009, 80, 1421-1432.

4. Page, R.C.; Kornman, K.S. The pathogenesis of human periodontitis: An introduction. Periodontology 2000 1997, 14, 9-11.

5. Benakanakere, M.; Kinane, D.F. Innate cellular responses to the periodontal biofilm. Front. Oral Biol. 2012, 15, 41-55.

6. Parameter on periodontal maintenance. American Academy of Periodontology. J. Periodontol. 2000, 71, 849-850.

7. Cohen, R.E. Research, Science and Therapy Committee, American Academy of Periodontology. Position paper: Periodontal maintenance. J. Periodontol. 2003, 74, 1395-1401.

8. Gaunt, F.; Devine, M.; Pennington, M.; Vernazza, C.; Gwynnett, E.; Steen, N.; Heasman, P. The cost-effectiveness of supportive periodontal care for patients with chronic periodontitis. J. Clin. Periodontol. 2008, 35, 67-82.

9. Silva, G.L.; Soares, R.V.; Zenóbio EG. Periodontal abscess during supportive periodontal therapy: A review of the literature. J. Contemp. Dent. Pract. 2008, 9, 82-91.

10. Herrera, D.; Roldán, S.; Sanz, M. The periodontal abscess: A review. J. Clin. Periodontol. 2000, 27, 377-386.

11. Argilés, A.; Mourad, G.; Mion, C. Seasonal changes in blood pressure in patients with end-stage renal disease treated with hemodialysis. N. Engl. J. Med. 1998, 339, 1364-1370. 
12. Modesti, P.A.; Morabito, M.; Bertolozzi, I.; Massetti, L.; Panci, G.; Lumachi, C.; Giglio, A.; Bilo, G.; Caldara, G.; Lonati, L.; et al. Weather-related changes in 24-hour blood pressure profile: effects of age and implications for hypertension management. Hypertension 2006, 47, 155-161.

13. Morabito, M.; Crisci, A.; Orlandini, S.; Maracchi, G.; Gensini, G.F.; Modesti, P.A. A synoptic approach to weather conditions discloses a relationship with ambulatory blood pressure in hypertensives. Am. J. Hypertens. 2008, 21, 748-752.

14. Ruhenstroth-Bauer, G.; Baumer, H.; Burkel, E.M.; Sönning, W.; Filipiak, B. Myocardial infarction and the weather: A significant positive correlation between the onset of heart infarct and $28 \mathrm{KHz}$ atmospherics-A pilot study. Clin. Cardiol. 1985, 8, 149-151.

15. Morabito, M.; Modesti, P.A.; Cecchi, L.; Crisci, A.; Orlandini, S.; Maracchi, G.; Gensini, G.F. Relationships between weather and myocardial infarction: A biometeorological approach. Int. J. Cardiol. 2005, 105, 288-293.

16. Shanks, N.J.; Papworth, G. Environmental factors and heatstroke. Occupational Med. 2001, 51, 45-49.

17. Ohshige, K.; Hori, Y.; Tochikubo, O.; Sugiyama, M. Influence of weather on emergency transport events coded as stroke: Population-based study in Japan. Int. J. Biometeorol. 2006, 50, 305-311.

18. Macgregor, D.M. Effect of weather on attendance with injury at a paediatric emergency department. Emerg. Med. J. 2003, 20, 204-205.

19. Plavcová, E.; Kyselý, J. Relationships between sudden weather changes in summer and mortality in the Czech Republic, 1986-2005. Int. J. Biometeorol 2010, 54, 539-551.

20. Hanashiro, K.; Tamaki, N.; Kosugi, T.; Kakazu, T.; Kaneshima, H.; Saito, A. The correlation between the outbreaks of asthma attack and meteorologic parameters in Okinawa. Arerugi. 1998, 47, 434-448.

21. Suarez-Varela, M.M.; Alvarez, L.G.M.; Kogan, M.D.; Gonzalez, A.L.; Gimeno, A.M.; Ontoso, I.A.; Diaz, C.G.; Pena, A.A.; Aurrecoechea, B.D.; Monge, R.M.B.; et al. Climate and prevalence of atopic eczema in 6- to 7-year-old school children in Spain. ISAAC Phase Ш. Int. J. Biometeorol. 2008, 52, 833-840.

22. Yang, A.C.; Huang, N.E.; Peng, C.-K.; Tsai, S.-J. Do seasons have an influence on the incidence of depression? The use of an internet search engine query data as a proxy of human affect. PLoS One 2010, 5, e13728.

23. Henríquez-Sánchez, P.; Doreste-Alonso, J.; Martínez-González, M.A.; Bes-Rastrollo, M.; Gea, A.; Sánchez-Villegas, A. Geographical and climatic factors and depression risk in the SUN project. Eur. J. Public Health 2014, 24, 626-631.

24. Drane, D.; Berry, G.; Bieri, D.; McFarlane, A.C.; Brooks, P. The association between external weather conditions and pain and stiffness in women with rheumatoid arthritis. J. Rheumatol. 1997, 24, 1309-1316.

25. Strusberg, I.; Mendelberg, R.C.; Serra, H.A.; Strusberg, A.M. Influence of weather conditions on rheumatic pain. J. Rheumatol. 2002, 29, 335-338.

26. Macfarlane, T.V.; McBeth, J.; Jones, G.T.; Nicholl, B.; Macfarlane, G.J. Whether the weather influences pain? Results from the EpiFunD study in North West England. Rheumatology 2010, 49, $1513-1520$. 
27. Edefonti, V.; Bravi, F.; Cioffi, I.; Capuozzo, R.; Ammendola, L.; Abate, G.; Decarli, A.; Ferraroni, M.; Farella, M.; Michelotti, A. Chronic pain and weather conditions in patients suffering from temporomandibular disorders: a pilot study. Community Dent. Oral Epidemiol.2012, 40, 56-64.

28. Kloss-Brandstätter, A.; Hächl, O.; Leitgeb, P.C.; Buchner, A.; Coassin, S.; Rasse, M.; Kronenberg, F.; Kloss, F.R. Epidemiologic evidence of barometric pressure changes inducing increased reporting of oral pain. Eur. J. Pain 2011, 15, 880-844.

29. McWilliams, S.; Kinsella, A.; O'Callaghan, E. The effects of daily weather variables on psychosis admissions to psychiatric hospitals. Int. J. Biometeorol. 2013, 57, 497-508.

30. Machida, T.; Tomofuji, T.; Ekuni, D.; Yamane, M.; Yoneda, T.; Kawabata, Y.; Kataoka, K.; Tamaki, N.; Morita, M. Longitudinal relationship between plasma reactive oxygen metabolites and periodontal condition in the maintenance phase of periodontal treatment. Dis. Markers 2014, 2014, doi:10.1155/2014/489292.

31. Armitage, G.C. Development of a classification system for periodontal diseases and conditions. Ann. Periodontol. 1999, 4, 1-6.

32. Tomita, S.; Kasai, S.; Imamura, K.; Ihara, Y.; Kita, D.; Ota, K.; Sekino, J.; Nakagawa, T.; Saito, A. Changes in antimicrobial susceptibility profile and prevalence of quinolone low-sensitive strains in subgingival plaque from acute periodontal lesions after systemic administration of sitafloxacin. Microb. Pathog. 2015, 79, 41-46.

33. Aldeyab, M.A.; Harbarth, S.; Vernaz, N.; Kearney, M.P.; Scott, M.G.; DarwishElhajji, F.W.; Aldiab, M.A.; McElnay, J.C. The impact of antibiotic use on the incidence and resistance pattern of extended-spectrum beta-lactamase-producing bacteria in primary and secondary healthcare settings. Br. J. Clin. Pharmacol. 2012, 74, 171-179.

34. Herrera, D.; Alonso, B.; de Arriba, L.; Santa Cruz, I.; Serrano, C.; Sanz, M. Acute periodontal lesions. Periodontology 2000. 2014, 65, 149-177.

35. Zhou, Q.; Amar, S. Identification of proteins differentially expressed in human monocytes exposed to Porphyromonas gingivalis and its purified components by high-throughput immunoblotting. Infect. Immun. 2006, 74, 1204-1214.

36. Gokyu, M.; Kobayashi, H.; Nanbara, H.; Sudo, T.; Ikeda, Y.; Suda, T.; Izumi, Y. Thrombospondin-1 production is enhanced by Porphyromonas gingivalis lipopolysaccharide in THP-1 cells. PLoS One 2014, 9, e115107.

37. Barksby, H.E.; Nile, C.J.; Jaedicke, K.M.; Taylor, J.J.; Preshaw, P.M. Differential expression of immunoregulatory genes in monocytes in response to Porphyromonas gingivalis and escherichia coli lipopolysaccharide. Clin. Exp. Immunol.2009, 156, 479-487.

38. Thurnheer, T.; Belibasakis, G.N.; Bostanci, N. Colonisation of gingival epithelia by subgingival biofilms in vitro: Role of "red complex" bacteria. Arch Oral Biol. 2014, 59, 977-986.

39. Hodges, F.R. Barodontalgia at 12,000 feet. J. Am. Dent. Assoc. 1978, 97, 66-68.

40. Fledelius, H.C. High atmospheric pressure and myopic shift in caisson workers. Lancet. 2003, 361, 362.

41. Muhm, J.M.; Rock, P.B.; McMullin, D.L.; Jones, S.P.; Lu, I.L.; Eilers, K.D.; Space, D.R.; McMullen, A. Effect of aircraft-cabin altitude on passenger discomfort. N. Engl. J. Med. 2007, 357, $18-27$. 
42. Doherty, M.J.; Youn, C.E.; Haltiner, A.M.; Watson, N.F. Do weather-related ambient atmospheric-pressure changes influence sleep disordered breathing? J. Clin. Sleep Med. 2010, 6, $152-156$.

43. Brown, H.K.; Simpson, A.J.; Murchison, J.T. The influence of meteorological variables on the development of deep venous thrombosis. Thromb. Haemost. 2009, 102, 676-682.

44. Zadik, Y. Barodontalgia. J. Endod. 2009, 35, 481-485.

45. Sato, J.; Takanari, K.; Omura, S.; Mizumura, K. Effects of lowering barometric pressure on guarding behavior, heart rate and blood pressure in a rat model of neuropathic pain. Neurosci. Lett. 2001, 299, 17-20.

46. Funakubo, M.; Sato, J.; Honda, T.; Mizumura, K. The inner ear is involved in the aggravation of nociceptive behavior induced by lowering barometric pressure of nerve injured rats. Eur. J. Pain. 2010, 14, 32-39.

47. Jentsch, H.F.; März, D.; Krüger, M. The effects of stress hormones on growth of selected periodontitis related bacteria. Anaerobe 2013, 24, 49-54.

48. Analitis, A.; Katsouyanni, K.; Biggeri, A.; Baccini, M.; Forsberg, B.; Bisanti, L.; Kirchmayer, U.; Ballester, F.;Cadum, E.; Goodman, P.G.; et al. Effects of cold weather on mortality: Results from 15 European cities within the PHEWE project. Am. J. Epidemiol. 2008, 168, 1397-1408.

49. Basu, R. High ambient temperature and mortality: A review of epidemiologic studies from 2001 to 2008. Environ. Health 2009, 8, 40.

50. Goldberg, M.S.; Gasparrini, A.; Armstrong, B.; Valois, M.F. The short-term influence of temperature on daily mortality in the temperate climate of Montreal, Canada. Environ. Res. 2011, $111,853-860$.

51. Breitner, S.; Wolf, K.; Devlin, R.B.; Diaz-Sanchez, D.; Peters, A.; Schneider, A. Short-term effects of air temperature on mortality and effect modification by air pollution in three cities of Bavaria, Germany: A time-series analysis. Sci. Total Environ. 2014, 485-486, 49-61.

52. Koken, P.J.; Piver, W.T.; Ye, F.; Elixhauser, A.; Olsen, L.M.; Portier, C.J. Temperature, air pollution, and hospitalization for cardiovascular diseases among elderly people in Denver. Environ. Health Perspect. 2003, 111, 1312-1317.

53. Barnett, A.G.; Dobson, A.J.; McElduff, P.; Salomaa, V.; Kuulasmaa, K.; Sans, S. Cold periods and coronary events: An analysis of populations worldwide. J. Epidemiol. Community Health 2005, 59, 551-557.

54. Schäuble, C.L.; Hampel, R.; Breitner, S.; Rückerl, R.; Phipps, R.; Diaz-Sanchez, D.; Devlin, R.B.; Carter, J.D.; Soukup, J.; Silbajoris, R.; et al. Short-term effects of air temperature on blood markers of coagulation and inflammation in potentially susceptible individuals. Occup. Environ. Med. 2012, 69, 670-678.

55. Schneider, A.; Panagiotakos, D.; Picciotto, S.; Katsouyanni, K.; Löwel, H.; Jacquemin, B.; Lanki, T.; Stafoggia, M.; Bellander, T.; Koenig, W.; et al. Air temperature and inflammatory responses in myocardial infarction survivors. Epidemiology 2008, 19, 391-400.

56. D'Amato, G.; Cecchi, L. Effects of climate change on environmental factors in respiratory allergic diseases. Clin. Exp. Allergy 2008, 38, 1264-1274.

57. Steffens, D.; Maher, C.G.; Li, Q.; Ferreira, M.L.; Pereira, L.S.M.; Koes, B.W.; Latimer, J. Effect of weather on back pain: Results from a case-crossover study. Arthritis Care Res. 2014, 66, 1867-1872. 
58. Ahl, D.R.; Hilgeman, J.L.; Snyder, J.D. Periodontal emergencies. Dent. Clin. North Am. 1986, 30, 459-472.

59. Lewis, M.A.; Meechan, C.; MacFarlane, T.W.; Lamey, P.J.; Kay, E. Presentation and antimicrobial treatment of acute orofacial infections in general dental practice. Br. J. Oral Maxillofac. Surg. 1989, $166,41-45$.

60. Gray, J.L.; Flanary, D.B.; Newell, D.H. The prevalence of periodontal abscess. J. Indiana Dent. Assoc. 1994, 73, 18-23.

61. Kaldahl, W.B.; Kalkwarf, K.L.; Patil, K.D.; Molvar, M.P.; Dyer, J.K. Long term evaluation of periodontal therapy (I). Response to 4 therapeutic modalities. J. Periodontol. 1996, 67, 93-102.

62. McLeod, D.E.; Lainson, P.A.; Spivey, J.D. Tooth loss due to periodontal abscess: A retrospective study. J. Periodontol. 1997, 68, 963-966.

(C) 2015 by the authors; licensee MDPI, Basel, Switzerland. This article is an open access article distributed under the terms and conditions of the Creative Commons Attribution license (http://creativecommons.org/licenses/by/4.0/). 